Check for updates

Cite this: RSC Adv., 2018, 8, 37681

Received 21st September 2018

Accepted 31st October 2018

DOI: $10.1039 / c 8 r a 07873 d$

rsc.li/rsc-advances

\section{Hydroxylation and self-assembly of colloidal hydrogenated nanodiamonds by aqueous oxygen radicals from atmospheric pressure plasma jet $\uparrow$}

\author{
Vít Jirásek, (D) *ab Štěpán Stehlík, (D) a Pavla Štenclová, (D) a Anna Artemenko, (D) a \\ Bohuslav Rezek (iD ac and Alexander Kromka ${ }^{a}$
}

Plasma chemical surface modification of nanoparticles in gas-liquid type reactors enables a controllable, specific, low-cost, and environmentally friendly alternative to wet chemistry methods or thermal and dry plasma treatments. Here the atmospheric pressure radio-frequency microplasma jet ( $\mu$-APPJ) operating with $0.6 \% \mathrm{O}_{2}$ in $\mathrm{He}$ is used to deliver aqueous oxygen radicals (AOR) to the surface of $\sim 3 \mathrm{~nm}$ hydrogenated detonation nanodiamonds (H-DNDs) suspended in water. The AOR-treated H-DND samples are characterized by FTIR and XPS spectroscopies and by AFM and SEM imaging. The main chemical reaction mechanism is identified as the abstraction of surface hydrogen atoms by $\mathrm{O}$ or $\mathrm{OH}$ radicals and a consequent attachment of the $\mathrm{OH}$ group, thereby increasing concentration of alcohols, carboxyls, and aldehydes on the DND's surface. FTIR spectra reveal also a structural re-arrangement of the surface water on the AOR-treated H-DNDs. Yet zeta-potential of AOR-treated H-DNDs still remains positive (decreases from $+45 \mathrm{mV}$ to $+30 \mathrm{mV}$ ). The chemical modification gives rise to formation of nanoscale chain-like aggregates when AOR-treated H-DNDs are deposited on Si substrate.

\section{Introduction}

Diamond nanoparticles, or nanodiamonds (NDs), recently established themselves in a family of nanomaterials extensively studied in both basic and applied research. The uniqueness of NDs is given by the high rigidity of the diamond core and variable surface chemistry provided by the character of carbon as a building element of organic compounds. ${ }^{1-3}$ Engineering of NDs' surface in terms of chemistry and structure $\left(\right.$ e.g. $\mathrm{sp}^{3} / \mathrm{sp}^{2}$ carbon ratio, termination of surface carbons) is an essential step in developing suitable nanomaterial especially for bioapplications. ${ }^{4,5}$

Grafting of numerous functional groups on ND's surface is being used to establish a linking interface to other substances, like biomolecules or drugs. Another aim in modifying the surface of NDs' is to tune their physico-chemical properties, like the surface potential or hydrophilicity/hydrophobicity. Such a tuning might, for instance, control the NDs' aggregation, ${ }^{6}$ electrostatically-driven attachment to various substrates ${ }^{7-9}$ or efficiency of filling the composites. ${ }^{\mathbf{1 0 , 1 1}}$

\footnotetext{
'Institute of Physics, Czech Academy of Sciences, Cukrovarnická 10, 16021 Prague 6, Czech Republic.E-mail: jirasek@fzu.cz; Tel: +420-266053113

${ }^{b}$ Institute of Plasma Physics, Czech Academy of Sciences, Za Slovankou 1782/3, 18200 Prague 8, Czech Republic

${ }^{c}$ Faculty of Electrical Engineering, Czech Technical University, Technická 2, 16627 Prague 6, Czech Republic
}

† Electronic supplementary information (ESI) available. See DOI: 10.1039/c8ra07873d
A plasma chemical approach as a surface chemistry modification tool brings several benefits over other more conventional methods represented by wet chemistry or thermal treatments. Firstly, it usually does not require the use of toxic or hazardous chemicals. Secondly, production of specific reactive species, namely free radicals, can be optimized by adjusting discharge parameters, gas mixtures, and experimental arrangement. This may promote specific modifications of the nanoparticles' surface which are not easily achieved by the conventional methods.

Various attempts were examined to modify the surface chemistry of a dry nanodiamond powder in established types of plasmatic reactors, including the hydrogenation in microwave CVD reactor, ${ }^{12}$ oxidation in $\mathrm{RF} \mathrm{O}_{2}$ plasma, ${ }^{13}$ or hydrogenation ${ }^{14}$ and amination $^{15}$ in dielectric coplanar surface barrier discharge. However, these "dry" plasma chemical methods commonly suffer from inhomogeneous and inefficient treatment of the whole particles' surface, especially if the particles are in an aggregated state such as conventional detonation nanodiamond (DND).

Modern non-equilibrium atmospheric pressure plasma sources enable to ignite a discharge in or above liquid supplying highly reactive environment without any thermal load on the sample. ${ }^{16}$ Therefore, approaches working with the NDs in a liquid suspension are considered promising. Prior experiments in that way ${ }^{17-19}$ resulted predominantly in moderate, specific oxidations of the ND's surface. The underwater pulsed streamer corona discharge treatment of DNDs in saline solution ${ }^{\mathbf{1 7}}$ induced a moderate oxidation with epoxides as a specific moiety created by plasma oxidation. The treatment, however, also caused 
a pronounced change of nanodiamonds' physical properties. Their zeta potential (ZP) changed from $+40 \mathrm{mV}$ to $-20 \mathrm{mV}$, leading subsequently to their agglomeration and formation of long filaments. Nanodiamonds in water suspension were also treated by RF (450 MHz) quartz capillary jet. ${ }^{18}$ This treatment increased the oxygen content and decreased $\mathrm{ZP}$ from $+58 \mathrm{mV}$ to $+31 \mathrm{mV}$ as well. Milder approach used the afterglow of DC corona or transient-spark discharge in the air above the suspension. ${ }^{\mathbf{1 9}}$ The observed minor chemical changes were interpreted as a rearrangement of oxygen-containing surface functional groups rather than direct oxidation of the NDs.

Recently, significant progress in understanding the atmospheric pressure plasma jets (APPJ) physics ${ }^{\mathbf{2 0 , 2 1}}$ and chemistry ${ }^{\mathbf{2 1}}$ was achieved. This gave rise to an increasing number of proposed APPJ applications, namely in medicine $e^{22,23}$ and material processing. ${ }^{\mathbf{2 4 , 2 5}}$ LOw temperature (LT) APPJs operating with noble gas with $\mathrm{O}_{2}$ or $\mathrm{H}_{2} \mathrm{O}$ admixtures were found to generate high concentrations of strongly oxidizing $\mathrm{O}$ or $\mathrm{OH}$ radicals in water solutions. ${ }^{26,27}$ By measuring degradation of phenol in water, it was recently shown ${ }^{27}$ that for $\mathrm{He} / \mathrm{O}_{2}$ plasma, oxidation was driven mainly by $\mathrm{O}$ atoms, and, by contrast, in $\mathrm{He} / \mathrm{H}_{2} \mathrm{O}$ and $\mathrm{He} / \mathrm{O}_{2} / \mathrm{H}_{2} \mathrm{O}$ plasmas, oxidation appeared to be driven by $\mathrm{OH}$ radicals. Several other studies ${ }^{\mathbf{2 6}, 28-30}$ have stated that introducing humidity into working gas dramatically decreases $\mathrm{O}$ atoms concentration. Briefly, it can be said that introducing water vapour into the plasma jet may switch from O-rich to OH-rich conditions.

The oxidation of carbon nanomaterials with oxygen radicals provided by LT APPJ was reported only rarely. The $\mathrm{Ar} / \mathrm{O}_{2}(30: 1)$ plasma jet fully immersed in the liquid was used for the treatment of carbon nanowalls. ${ }^{31}$ As a consequence of the plasma treatment, the chemical composition at surface evolved towards the incorporation of oxygen functionalities. The treatment also favored the attachment of smaller particles to larger particles. As another example, the APPJ with $1 \% \mathrm{O}_{2}$ in He was successfully used to remove non-diamond carbon from raw DND powder treated in the form of pellets. ${ }^{32}$ In addition, the process was applied to a direct writing onto an ND/polymer composite layer to create an arbitrary pattern with high spatial resolution and high purity of ND. The atomic oxygen was mentioned as a probable oxidizing specie in this case.

In this paper we characterize activity of the APPJ supplied reactive oxygen species (ROS) towards the surface modification of individual hydrogenated NDs in a colloidal solution. We identify and describe specific oxidation mechanisms via aqueous oxygencontaining radicals (AOR) like $\mathrm{O}$ or $\mathrm{OH}$ species. We also show impact of the modification on self-assembly of nanodiamonds on substrates.

\section{Experimental}

\subsection{Plasma treatment}

The apparatus consists of the $\mu$-APPJ plasma source connected to a small chamber with the working solution (see Fig. 1). The plasma source is a clone of the so-called COST Reference jet ${ }^{33}$ and the experimental arrangement is similar to that described in Hefny et al. ${ }^{27}$ Briefly, plasma is ignited within the small, $1 \times 1 \times$
$30 \mathrm{~mm}$ volume by the $13.56 \mathrm{MHz}$ sinusoidal voltage of $235 \mathrm{~V}$ rootmean-square (the absorbed power $<2 \mathrm{~W}$ ).

As a feed gas, helium with the flow of 1.4 standard liters per minute (slm) was used, with the admixture of $0.6 \%(8.4 \mathrm{sccm})$ of oxygen. The outlet of jet nozzle was placed $4 \mathrm{~mm}$ above the liquid surface so that the visible plasma channel was not in direct contact with the liquid. The chamber consisted of a small, $6 \mathrm{ml}$ glass cylinder filled by $3 \mathrm{ml}$ of the working colloidal solution. The whole system was closed from the surrounding atmosphere by an aluminum cover with an integrated gas exhaust line sealed by the flat rubber ring. Before each experiment, the whole gas inlet tubing was purged by $0.2 \mathrm{slm} \mathrm{He}+8.4 \mathrm{sccm} \mathrm{O}_{2}$ for at least $30 \mathrm{~min}$ in order to remove ambient air. The sealed chamber with the working solution was then yet purged for 2 min by the final working gas mixture to obtain saturated steady-state conditions. Optimizing this purge time lead to the absence of detectable $\left(>1 \times 10^{-6} \mathrm{M}\right)$ amount of $\mathrm{NO}_{2}{ }^{-}$and very low concentration of $\mathrm{H}_{2} \mathrm{O}_{2}$. The described conditions were found to lead to the production of $\mathrm{O}$ atoms as the major reactive oxygen species (ROS). ${ }^{34}$ Nevertheless, since also the $\mathrm{OH}$ radical takes part in the process, the described plasma treatment is referenced in the text as the "aqueous oxygencontaining radical" treatment or the AOR treatment.

\subsection{DNDs preparations and physical characterization}

As nanodiamonds we used a commercial DND powder from New Metals and Chemicals, Japan, with a declared nominal size of $5 \mathrm{~nm}$. In order to remove possible residual $\mathrm{sp}^{2}$ carbon and to oxidize the DND surface $400 \mathrm{mg}$ of the as-received DNDs were annealed in air at $450{ }^{\circ} \mathrm{C}$ for 30 minutes. About $200 \mathrm{mg}$ of such treated DND powder was then subjected to annealing in pure hydrogen gas performed in a quartz reactor at $700{ }^{\circ} \mathrm{C}$ for 6 hours at an atmospheric pressure of hydrogen. $20 \mathrm{mg}$ of the obtained $\mathrm{H}$ DNDs were then dispersed in DI water by means of ultrasonication using a sonotrode (Hielscher 200) lasting for one hour. The $2 \mathrm{ml}$ dispersion was centrifuged (Eppendorf Mini plus) at $14000 \times g$ for $1 \mathrm{~h}$ and $1 \mathrm{ml}$ of clear, brownish (approx. H-DND concentration was $2-3 \mathrm{mg} \mathrm{ml}^{-1}$ ) supernatant was then carefully separated by a micropipette. Dynamic light scattering (DLS) and zeta potentials were measured on Malvern Zetasizer Nano ZS equipped with a helium-neon laser $(633 \mathrm{~nm})$ at $25{ }^{\circ} \mathrm{C}$; the scattering angle was $173^{\circ}$. A disposable folded capillary cells were used to eliminate sample cross contamination. DLS measurements were carried out at $20^{\circ} \mathrm{C}$, refractive index of bulk diamond (2.4) and viscosity of pure water (1002 Pa s) at $20^{\circ} \mathrm{C}$ was used. The DLS data were plotted as volume/size distributions. The H-DND as well as $\mu$-APPJ plasma treated H-DNDs were deposited on clean p-type Si wafers by immersion of the Si substrates into the ND colloids while $10 \mathrm{~min}$ sonication in an ultrasonic bath. After the deposition, the Si wafers were rinsed by DI water and blown by nitrogen. Atomic force microscopy (AFM, Ntegra Prima, NT-MDT) images were acquired in a non-contact regime with approximate cantilever (Nanosensors PPP $150 \mathrm{kHz}$ ) oscillation amplitude of $5 \mathrm{~nm}$. The scan range was 200 to $500 \mathrm{~nm}$ at the resolution of $512 \times 512$ points. SEM (MAIA 3, Tescan) images of the deposited DNDs on Si wafers were obtained at acceleration voltage of $15 \mathrm{kV}$ and $300 \mathrm{k}$ magnification in the regime of secondary electrons. 
a)

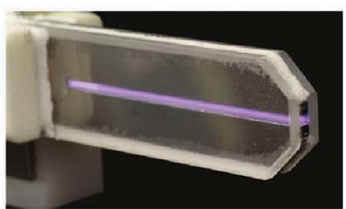

b)

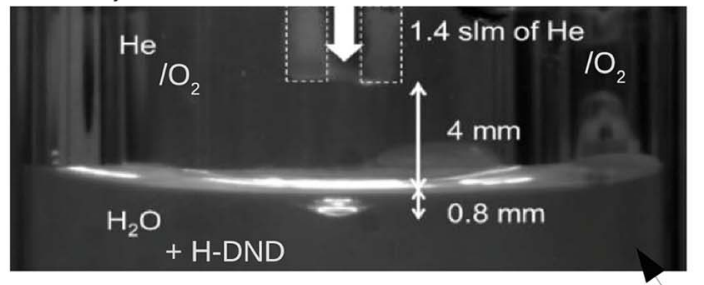

c)

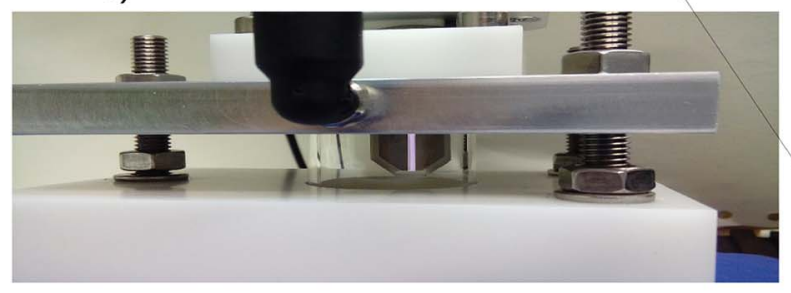

gas outlet $\mathrm{He}+\mathrm{O}_{2}$

d)

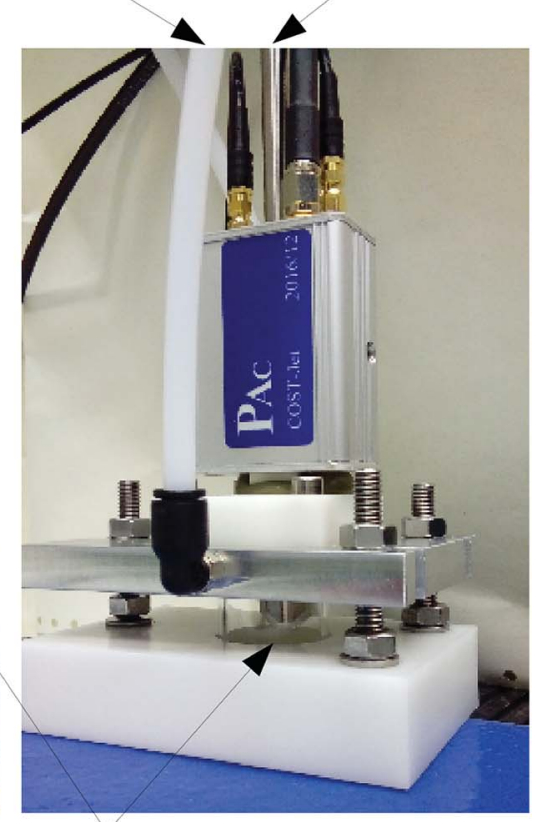

H-DND suspension

Fig. 1 Experimental setup. Closed-up views of the discharge chamber (a), arrangement of the jet with the liquid suspension (b and c) and the whole reactor (d).

\subsection{FTIR spectroscopy}

Surface chemistry of DND particles before and after the AOR treatment was characterized by grazing angle reflectance Fourier transform infrared (GAR-FTIR) spectroscopy. IR absorbance spectra were measured using an $\mathrm{N}_{2}$ purged Thermo Nicolet 870 spectrometer equipped with the KBr beam splitter and MCT-D detector cooled by liquid nitrogen. A $100 \mu \mathrm{l}$ of the DND aqueous colloidal solution was applied on the Au mirror by a drop casting just before the GAR-FTIR measurement. Solutions on Au mirrors were heated at $100^{\circ} \mathrm{C}$ for 2 min to evaporate water, these samples are denoted as "short-dried". All samples were additionally dried at $10^{-7} \mathrm{mbar}$ while heating to $100^{\circ} \mathrm{C}$ for 4 days. These samples are denoted as "in vacuo dried". Optical absorbance was calculated in the standard absorbance units as $A=-\log \left(R / R_{0}\right)$, where $R$ is the spectrum measured with NDs and $R_{0}$ is the reference (background) spectrum recorded using clean $\mathrm{Au}$ mirror prior to the NDs application. In all cases, the spectra represent an average of 128 scans recorded with a resolution of $4 \mathrm{~cm}^{-1}$.

The interpretation of the taken FTIR spectra was based on general tables and books ${ }^{35,36}$ as well as on other works. ${ }^{37-41}$ For reference, the assignments of the peak wavenumbers to individual vibrational modes are summarized in Table 1.

\subsection{XPS spectroscopy}

The X-ray photoelectron spectrometer (Kratos, AXIS Supra) equipped with a hemispherical analyser and a monochromatic Al K $\alpha$ X-ray source $(1486.6 \mathrm{eV})$ was used for estimation of the chemical composition of the NDs. The XPS spectra were acquired at a constant $90^{\circ}$ take-off angle from the analysed area about $700 \times 300 \mathrm{~mm}^{2}$. The survey XPS spectra were recorded with the pass energy of $80 \mathrm{eV}$, whereas the high-resolution spectrum scans were recorded with the pass energy of $20 \mathrm{eV}$. The measured spectra were processed in Casa XPS software with Shirley background correction procedure and Gaussian line shapes of variable widths. The samples for XPS analysis were prepared in the same way as for the IR analysis, which means by drop casting the colloidal suspension on Au substrate and heating on a hot plate at $100{ }^{\circ} \mathrm{C}$ until dry.

\section{Results and discussion}

\subsection{Chemical analysis by FTIR}

3.1.1 Overall spectral changes on treated H-DNDs. Fig. 2 shows the FTIR spectra of the as-received DND material and DND's subsequently treated by air-annealing, $\mathrm{H}_{2}$-annealing, and AOR for $60 \mathrm{~min}$.

The as-received DND's are decorated with various oxygencontaining groups, i.e. hydroxyls $\left(3800-2800 \mathrm{~cm}^{-1}\right)$, carbonyls $\left(1718 \mathrm{~cm}^{-1}\right.$ ), ethers and epoxides (mixed with $\mathrm{C}-\mathrm{O}-\mathrm{H}$ bending and various $\mathrm{CH}_{x}$ deformation modes in the broad "fingerprint" region $1500-800 \mathrm{~cm}^{-1}$ ). There is also a significant contribution of hydrogen-saturated carbon as manifested by the characteristic region of C-H stretching vibrations $\left(3050-2800 \mathrm{~cm}^{-1}\right)$.

The air-annealing resulted in the total removal of these $\mathrm{C}-\mathrm{H}$ bonds and the introduction of new carbonyl functions $\left(1800 \mathrm{~cm}^{-1}\right.$ : lactones, anhydrides, strongly coupled carboxyls $\left.{ }^{13,42}\right)$ and ethers ${ }^{13}\left(1275 \mathrm{~cm}^{-1}, 1115 \mathrm{~cm}^{-1}\right)$. The subsequent hydrogenation introduced again $\mathrm{C}-\mathrm{H}$ bonds and 
Table 1 FTIR peak (band) assignments

\begin{tabular}{|c|c|c|c|}
\hline$\omega, \mathrm{cm}^{-1}$ & Vibrational mode ${ }^{a}$ & $\omega, \mathrm{cm}^{-1}$ & Vibrational mode \\
\hline 3695 & $\nu \mathrm{OH}$, free (non $\mathrm{HB})$ & $1515-1670$ & $\delta \mathrm{N}-\mathrm{H}$ \\
\hline $2800-3650$ & $\nu \mathrm{OH}, \mathrm{HB}:$ alcohols (3310), carboxyls (3200) & 1645,1653 & $\delta \mathrm{H}_{2} \mathrm{O},\left(\mathrm{HB} \mathrm{H}_{2} \mathrm{O} \cdots \mathrm{H}_{2} \mathrm{O}\right)$, "bulk" \\
\hline $2943-47$ & $\nu \mathrm{CH}_{3}$, asymmetric & 1589 & $\delta \mathrm{H}_{2} \mathrm{O}$, non $\mathrm{HB}$, close to $\mathrm{C}-\mathrm{OH}$ \\
\hline $2952-57$ & $\nu \mathrm{C}-\mathrm{H}$, unassigned & $1560-72$ & $\delta \mathrm{H}_{2} \mathrm{O}$, non $\mathrm{HB}$, close to $\mathrm{C}-\mathrm{H}$ \\
\hline $2925-29$ & $\nu \mathrm{CH}_{2}$, asymmetric & 1466 & $\delta \mathrm{CH}_{2}$, scissoring \\
\hline $2742-60$ & $\delta \mathrm{C}-\mathrm{H}$, aldehyde $\left(1^{\text {st }}\right.$ overtone $)$ & 1379 & $\delta \mathrm{C}-\mathrm{H}$, aldehyde \\
\hline $2660-70$ & $\nu \mathrm{C}-\mathrm{H}$, aldehyde & $1270-1358$ & $\delta \mathrm{C}-\mathrm{O}-\mathrm{H}$, alcohol, carboxyl, $\nu \mathrm{C}-\mathrm{O}-\mathrm{C}$, ether, ester (asymmetric) \\
\hline $1780-1820$ & $\nu \mathrm{C}=\mathrm{O}$, anhydride, lactone & $1000-1220$ & $\nu \mathrm{C}-\mathrm{O}$, alcohol, carboxyl, $\nu \mathrm{C}-\mathrm{O}-\mathrm{C}$, ether, ester (symmetric) \\
\hline $1720-40$ & $\nu \mathrm{C}=\mathrm{O}$, carboxyl & 1195 & $\delta \mathrm{CH}_{2}$ (wagging, twisting)? \\
\hline $1690-1720$ & $\nu \mathrm{C}=\mathrm{O}$, aldehyde, ketone & 836 & $\delta \mathrm{CH}_{2}$ (rocking)? \\
\hline
\end{tabular}

removed oxygen in ethers and other $\mathrm{C}-\mathrm{O}$ bonds. The chemical reduction of highly oxidized carbons (lactones, anhydrides, carboxyls) led to the shift of the residual carbonyl peak back to low wavenumber representing lower oxidation states such as aldehydes and ketones. The substantial decrease of $\mathrm{C}-\mathrm{O}$ contributions in the fingerprint region by $\mathrm{H}_{2}$-annealing augmented the $>\mathrm{CH}_{2}$ scissoring $\left(1466 \mathrm{~cm}^{-1}\right)$ and $-\mathrm{CH}_{3}$ bending $\left(1385 \mathrm{~cm}^{-1}\right)$ modes, as well as the peak at $1331 \mathrm{~cm}^{-1}$, attributed to the one-phonon diamond mode which was found to appear in FTIR spectra due to the nitrogen substitutions in the diamond lattice. ${ }^{39}$ The sharp peaks emerging at $1195 \mathrm{~cm}^{-1}$ and $836 \mathrm{~cm}^{-1}$ would also correspond to $>\mathrm{CH}_{2}$ deformation modes, namely the twisting or wagging and rocking vibrations, respectively. Although these assignments are somewhat questionable, since still some residual $\mathrm{C}-\mathrm{O}$ stretch vibration may appear here, the correlation with the hydrogenation process favours the $\mathrm{CH}_{x}$ deformation vibrations. Note that the free $\mathrm{O}-\mathrm{H}$ stretch $\left(3695 \mathrm{~cm}^{-1}\right)$ is missing in the spectra of air-annealed NDs.
After the AOR treatment, a substantial increase of singlebonded oxygen groups (3800-2800 $\mathrm{cm}^{-1}$ and $1450-1000 \mathrm{~cm}^{-1}$ ) was found. However, in comparison with the air-annealing, the $\mathrm{CH}_{x}$ signatures and the $\mathrm{C}=\mathrm{O}$ band were much less affected.

Fig. 3 shows the evolution of the vibrational signatures with increasing time of the AOR treatment.

In these survey spectra, a subsequent increase of oxygencontaining surface groups, namely the $\mathrm{O}-\mathrm{H}$ stretching (3800$2800 \mathrm{~cm}^{-1}$ and $3695 \mathrm{~cm}^{-1}$ ) and $\mathrm{C}-\mathrm{O}$ single bond vibrations $\left(1450-1000 \mathrm{~cm}^{-1}\right)$ with the treatment time is clearly visible. The fine structure of the fingerprint band almost does not change up to $30 \mathrm{~min}$, but at 45 and $60 \mathrm{~min}$, increased contributions at $1124 \mathrm{~cm}^{-1}$ (C-O stretch) and $1309 \mathrm{~cm}^{-1}$ (C-O-H bend) are apparent. Due to the correlation with $\mathrm{O}-\mathrm{H}$ stretches increase, these contributions can be assigned to increasing concentration of alcohols or carboxyls on the AOR treated H-DNDs.

The above mentioned changes were similar on both shortdried and in vacuo dried samples - see Fig. 4.

However, local differences were found in the region of $\mathrm{C}-\mathrm{O}$ vibrations. From the spectra of short-dried samples, we see that

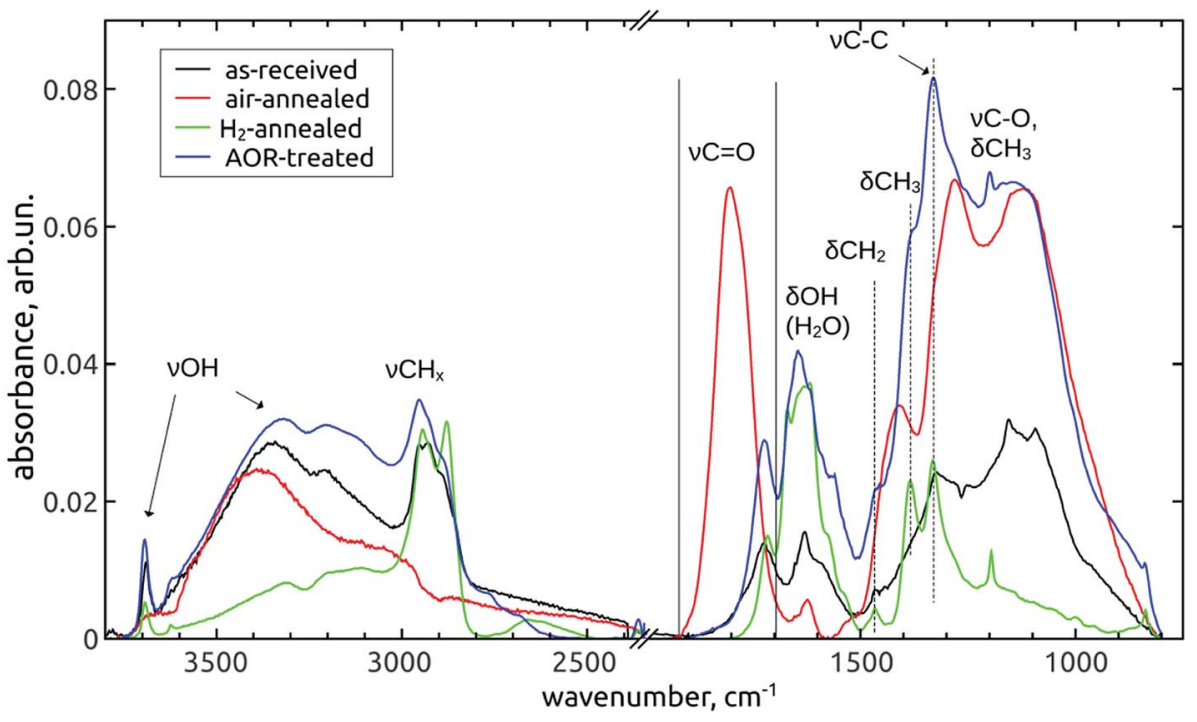

Fig. 2 FTIR spectra of as-received and subsequently air-annealed, $\mathrm{H}_{2}$-annealed and AOR-treated NDs. All samples were short-dried. 


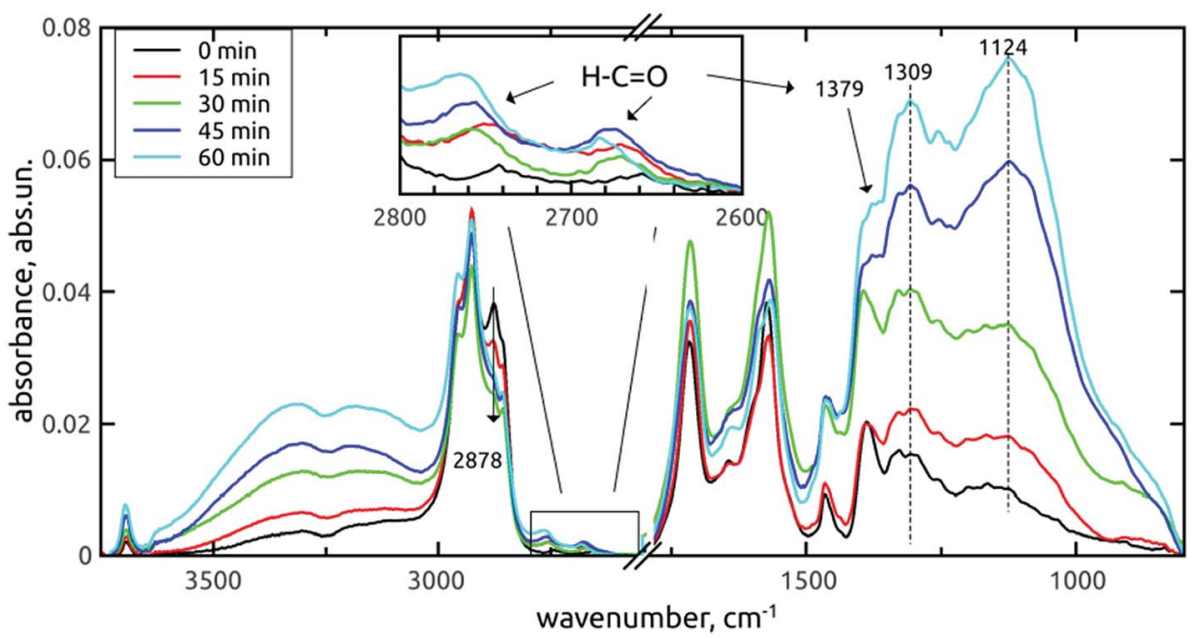

Fig. 3 FTIR spectra of H-DNDs modified by the AOR treatment for 0-60 min. Samples were dried in vacuo.

the increase of $1309 \mathrm{~cm}^{-1}$ peak is masked by the proximity of the one-phonon diamond peak $\left(1331 \mathrm{~cm}^{-1}\right)$. In addition, the whole $1400-800 \mathrm{~cm}^{-1}$ band, as it increases, its fine-structure is somewhat disappearing, although the two sharp peaks attributed to $\mathrm{CH}_{2}$ deformation vibrations remain well pronounced. On the other hand, the fine structure remains well resolved after 60 min AOR treatment in the case of in vacuo dried samples. This indicates a sensitivity of $\mathrm{C}-\mathrm{O}$ stretch and $\mathrm{C}-\mathrm{O}-\mathrm{H}$ bend modes to the formation of hydrogen bonds (HB) with adsorbed water molecules. In the case of alcohol surface $\mathrm{C}-\mathrm{OH}$ groups, high diversity exists as a result of primary, secondary and tertiary alcohols sitting on the different type of possible sites, and forming HB not only with the adsorbed water, but also between each other. This can lead to a high dispersion of vibrational frequencies and formation of a broad, continuous absorption band. We assume that this dispersion can explain the lower resolution of the band for the AOR-oxidized H-DND's, with the $\mathrm{CH}_{2}$ peaks remaining intact.

A very interesting result is the appearance of aldehydes with their typical doublet $\left(2742 \mathrm{~cm}^{-1}\right.$ and $2660 \mathrm{~cm}^{-1}$ for the reference H-DNDs, see the inset in Fig. 3), which are rather unique to nanodiamonds, taking into account the published literature. The $1379 \mathrm{~cm}^{-1}$ peak denoted in Fig. 3 and 4 was assigned to the aldehyde $\mathrm{C}-\mathrm{H}$ bending mode, whose $1^{\text {st }}$ overtone is in resonance with the $\mathrm{C}-\mathrm{H}$ stretch and forms the second $\mathrm{C}-\mathrm{H}$ mode at $2742 \mathrm{~cm}^{-1} .^{35}$ The apparent, yet rather small concentration of aldehydes on the reference H-DNDs is probably a result of carboxyls reduction to aldehydes by $\mathrm{H}_{2}$-annealing and can be regarded as specific for the used sequence of modifications of the as-received DND powder. All three aldehyde peaks increase with the AOR treatment time. Furthermore, the $2742 \mathrm{~cm}^{-1}$ mode is shifted towards higher values due to dynamic dipole coupling, ${ }^{43}$ as the concentration of aldehydes increases. The aldehydes contribution to the carbonyl peak $\left(1715 \mathrm{~cm}^{-1}\right)$ is less apparent, probably due to their low concentration. However, certain changes on the carbonyl peak can be still seen under higher magnification. This band belongs to the spectral region $\left(1800-1500 \mathrm{~cm}^{-1}\right)$ the most affected by water adsorption, as demonstrated in Fig. 4 too. The corresponding spectral part will be discussed separately in Section 3.1.3.

The band representing the $\mathrm{C}-\mathrm{H}$ stretches of alkane-type groups was modified, as indicated in Fig. 3, by decreasing the

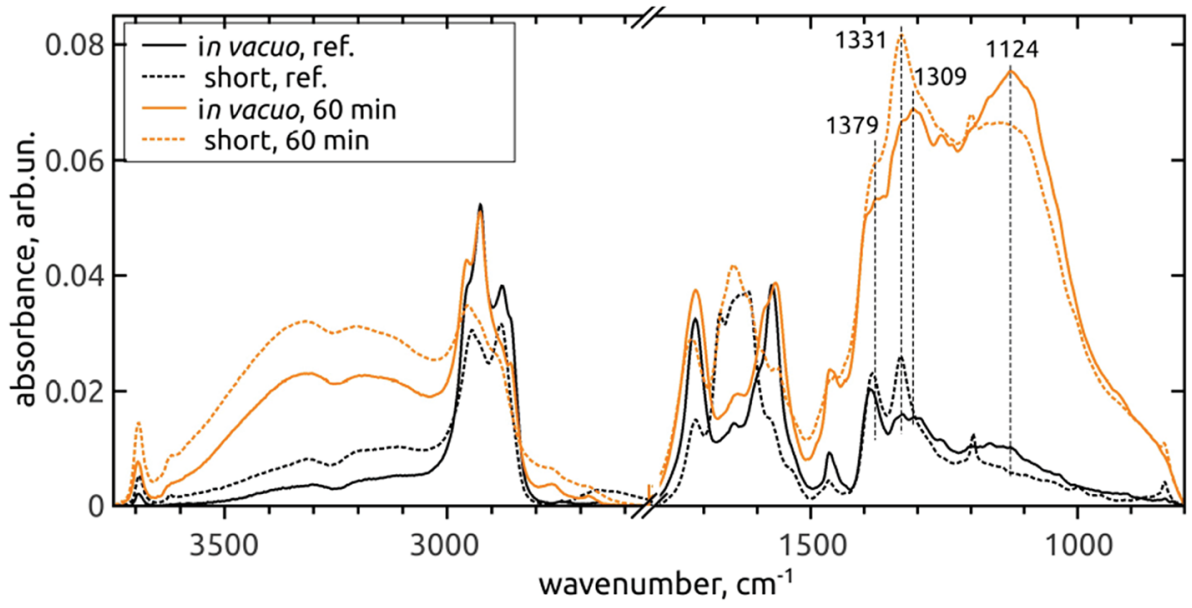

Fig. 4 Comparison of FTIR spectra of in vacuo dried (full line) and short-dried (dashed line) reference DNDs and 60 min AOR-treated H-DNDs. 
a)

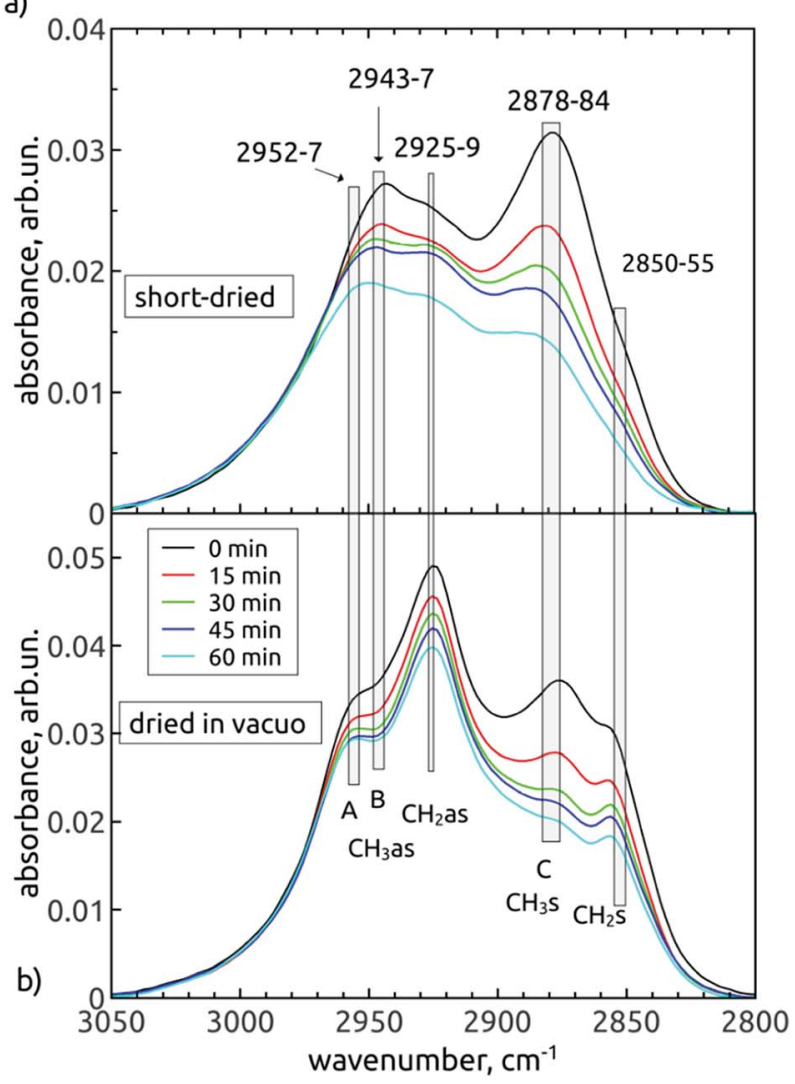

Fig. 5 FTIR spectra of the alkane-type $\mathrm{C}-\mathrm{H}$ stretch region of shortdried (a) and in vacuo dried (b) AOR-treated H-DNDs. The contributions with common temporal behaviour separated by more than $10 \mathrm{~cm}^{-1}$ are treated as individual vibrational modes. The span of their exact positions is denoted as the widths of the vertical grey bars. The spectra were baseline-corrected and rescaled for better clarity.

peak at $2878 \mathrm{~cm}^{-1}$ over the treatment time. This small, but specific oxidation of hydrogenated carbon is more corroborated and discussed in next section.

3.1.2 Chemical modification of $\mathrm{CH}_{x}$ groups. The details of spectral region $3050-2800 \mathrm{~cm}^{-1}$ are shown in Fig. 5 for both short-dried (a) and in vacuo dried (b) AOR-treated H-DNDs.

In different FTIR studies of NDs, most frequently four peaks are resolved in this spectral band. According to literature, ${ }^{38,39,41}$ these peaks would have to be attributed in both our spectral sets to different wavenumbers. The "better" representation, i.e. the dried in vacuo measurement, leads us to attribute asymmetric $\left(2925 \mathrm{~cm}^{-1}\right)$ and symmetric $\left(2857 \mathrm{~cm}^{-1}\right)$ stretches of the $-\mathrm{CH}_{2}$ group and asymmetric $\left(2954 \mathrm{~cm}^{-1}\right)$ and symmetric $\left(2878 \mathrm{~cm}^{-1}\right)$ stretches of the $-\mathrm{CH}_{3}$ group, respectively. However, in Fig. 5b, it follows that the peak "C" was steadily decreasing during the treatment duration relative to the strongest $2925 \mathrm{~cm}^{-1}$ mode. Since the decrease seems not to be accompanied by a substantial decrease of the $2954 \mathrm{~cm}^{-1}$ shoulder ("A", the proposed asymmetric partner), this would indicate that the " $\mathrm{C}$ " peak could be a signature of a monohydride vibration. However, the monohydride vibrations are generally of weak intensity ${ }^{35}$ and are present rather as a termination of dangling bonds on the surface of truly diamond crystalline lattice of $\{111\},\{110\}$ or $\{100\}-2 \times 1$ reconstructed surface. We suppose that area of such surfaces on our H-DND's will be much lower in comparison to more or less disordered $\mathrm{sp}^{3} / \mathrm{sp}^{2}$ carbon surface layer eventually decorated with small hydrocarbon residues.

The comparison of short-dried samples (Fig. 5a) with the in vacuo dried samples (Fig. $5 \mathrm{~b}$ ) becomes useful here. It is known that water adsorption influences relatively little the frequencies of collective symmetric and asymmetric $\mathrm{CH}_{x}$ stretches. ${ }^{35}$ Consequently, we suggested five vibrational modes common to both spectral sets, little shifted by the water adsorption. The observed shifts $\left(3-6 \mathrm{~cm}^{-1}\right)$ are denoted by the width of the grey bars in Fig. 5, while the individual bars denote contributions of individual vibration modes, common to both spectral series. Thus, we distinguish two contributions at the higherwavenumber edge, i.e. $2952-2957 \mathrm{~cm}^{-1}$ (contribution A) and 2943-2947 $\mathrm{cm}^{-1}$ (contribution B). While the contribution A does not change relatively to $\mathrm{CH}_{2}$ as, the contribution $\mathrm{B}$ decreases in time, together with the peak $\mathrm{C}$. The other common feature of " $\mathrm{B}$ " and " $\mathrm{C}$ " is their dominance in the spectra of short-dried samples over the $-\mathrm{CH}_{2}$ as peak. Interestingly, in the spectra of in vacuo dried samples, we found the reverse situation, i.e. the $-\mathrm{CH}_{2}$ as is dominant over the " $\mathrm{B}$ " and "C" peaks. The origin of this phenomenon is still unclear. Yet we can conclude that a common inspection of both short-dried and in vacuo dried time variations of spectral shapes enabled to reveal that there is a decrease in concentration of $-\mathrm{CH}_{3}$ groups (represented by $\mathrm{CH}_{3}$ as - contribution B and $\mathrm{CH}_{3} \mathrm{~S}$ - contribution C) during the AOR treatment.

Such an observation is fully consistent with the increased concentration of aldehydes, resulting from the radical oxidation of $-\mathrm{CH}_{3}$ groups in two reaction sequences. In the first reaction, $\mathrm{CH}_{3}$ group is oxidized to primary alcohol as

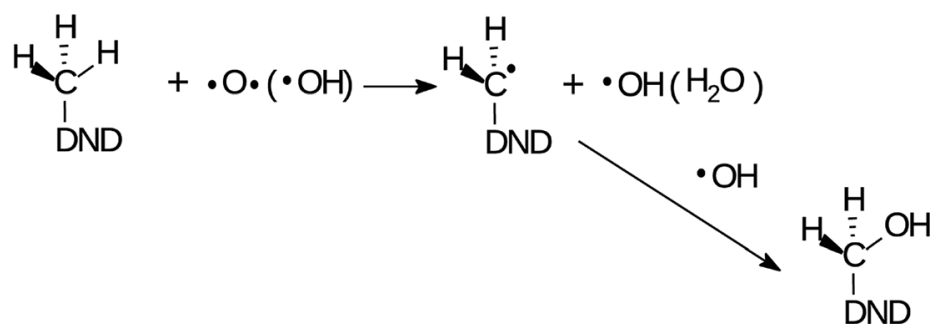


and in the second reaction, the alcohol is oxidized to aldehyde as of other vibrations, e.g. the $\mathrm{N}-\mathrm{H}$ bending modes, cannot be totally excluded.

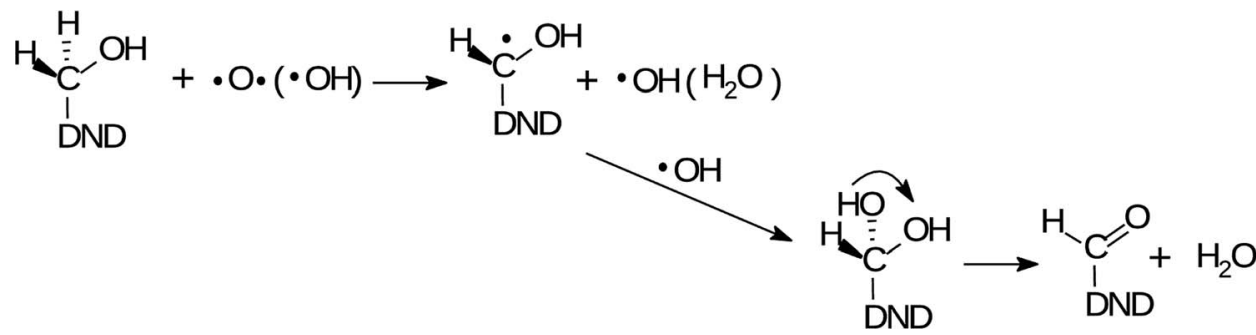

The $\mathrm{O}$ and $\mathrm{OH}$ radicals are denoted as the acting species in both reactions. It is known that the $\mu$-APPJ jet working with the $\mathrm{O}_{2} / \mathrm{He}$ gas mixture provides a high flux of $\mathrm{O}$ atoms. At the $\mathrm{O}_{2} / \mathrm{He}$ ratio of $0.6 \%$ the two other reactive oxygen species, $\mathrm{OH}$ and $\mathrm{O}_{3}$, are an order of magnitude lower. ${ }^{34}$ Since the ozone is little soluble in water, we will discuss the $\mathrm{O}$ and $\mathrm{OH}$ radical species. Both species have similar effects on hydrocarbons - the abstraction of hydrogen from the $\mathrm{C}-\mathrm{H}$ bond, forming the radical $\mathrm{C}^{*}$ site $\left(1^{\text {st }}\right.$ step in reactions (1) and (2)). This site will be saturated by single-bonding $\mathrm{OH}$, resulting either from the $1^{\text {st }}$ step, reaction of aqueous $\mathrm{O}$ atoms with $\mathrm{H}_{2} \mathrm{O}$, or delivered from the jet. The efficient hydroxylation of phenol in the same reactor system was reported ${ }^{27,44}$ with the evidence that the majority of $\mathrm{O}$ atoms forming the $-\mathrm{OH}$ groups originates from the plasma jet itself and not from water. Nevertheless, the effect of either $\mathrm{O}$ or $\mathrm{OH}$ produced from the jet and interacting with hydrocarbon residues on the NDs surface seems to be very similar. This assumption was fully confirmed in our experiments when we used humidified $\mathrm{He} / \mathrm{O}_{2}$ mixture (with $4000 \mathrm{ppm}$ of water vapour). The FTIR spectra (short-dried) of H-DNDs treated under these "OH-rich" conditions (see Section 1) were very similar to those measured under "O-rich" conditions (see Fig. S1 in the ESI $\dagger$ ). This supports the proposed reaction mechanisms (1) and (2) where the action of both radicals leads to the same products.

The two acting radicals are of course able to attack any $\mathrm{CH}_{x}$ site on the H-DND surface. It is therefore very probable that alcohol groups of all three types were formed in reactions of the type as a reaction (1) and contribute substantially to already discussed $\mathrm{O}-\mathrm{H}$ and $\mathrm{C}-\mathrm{O}$ FTIR signatures.

3.1.3 FTIR signatures of water bonded on AOR-treated ND's. The changes in the $1800-1500 \mathrm{~cm}^{-1}$ spectral region represent an interesting part of the FTIR spectra. As can be seen by comparison of Fig. 6 and 7, the spectra of short dried and in vacuo dried NDs are significantly different in this spectral region.

The difference observed between short-dried and in vacuo dried samples, together with conclusions from previous works ${ }^{37,45}$ indicates that almost all observed peaks in the range $1565-1660 \mathrm{~cm}^{-1}$ may be attributed to bending vibrations of the water molecules adsorbed on DND, although the contribution
The free, non-HB bending mode of gaseous water is $1589 \mathrm{~cm}^{-1} \cdot{ }^{37}$ The hydrogen bonding shifts the value to higher frequencies, in our case $1645 \mathrm{~cm}^{-1}$ for both short-dried and in vacuo dried H-DNDs and also 1615, 1635 and $1653 \mathrm{~cm}^{-1}$ for short-dried NDs. The highest mode, $1670 \mathrm{~cm}^{-1}$ (short-dried samples), is too far from the original free bending mode, but it is missing on in vacuo dried samples. It may be attributed to amide I band, since it is accompanied by $1536 \mathrm{~cm}^{-1}$ shoulder (possibly the amide II band) ${ }^{46}$ visible also only on the shortdried samples. The $1645 \mathrm{~cm}^{-1}$ mode was reported upon slight water adsorption on NDs with different surface functions, including hydrogenated NDs. ${ }^{37}$ This mode is probably the major "liquid" water component, since it greatly diminishes when the samples are dried in vacuo. Its increase in relation to other neighbouring modes by the AOR treatment (visible only on short-dried samples) indicates higher susceptibility to water adsorption on the AOR-treated NDs surfaces. This is different from DND's oxidized by air-annealing, which were found ${ }^{45}$ (by thermogravimetric analysis) to bound less water than H-DNDs. We assume that the main reason for this phenomenon is the different character of the oxidized surface after AOR treatment,

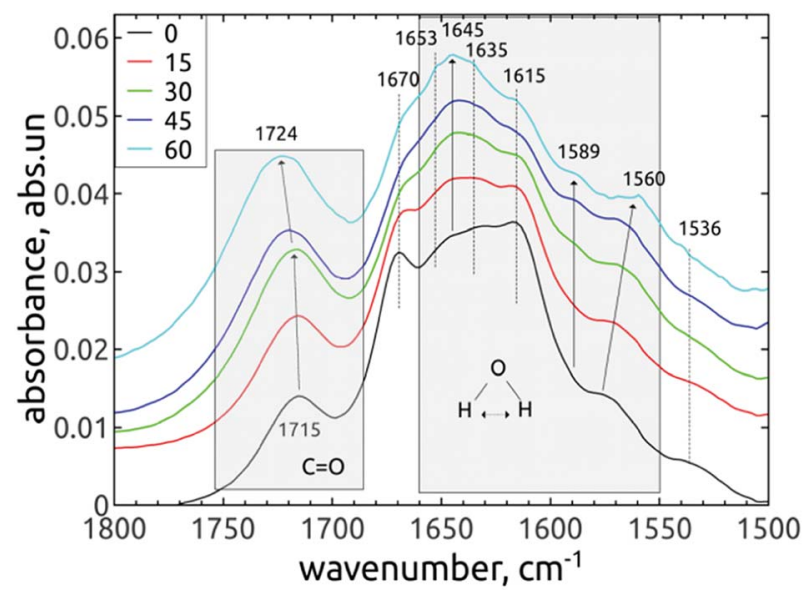

Fig. 6 FTIR spectra of short-dried H-DNDs in dependence on the AOR treatment time. The individual spectral lines are stacked for better clarity. The modes which change their relative intensity or position are marked with arrows. 


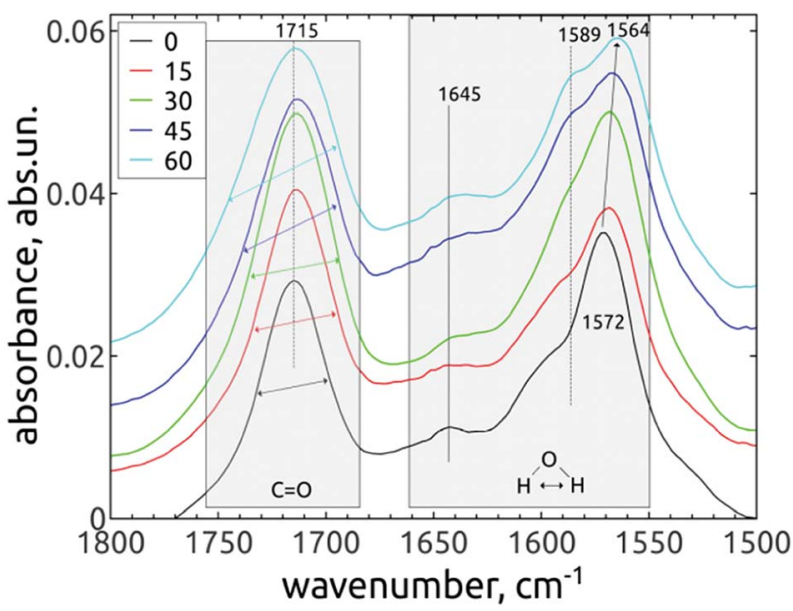

Fig. 7 FTIR spectra of in vacuo dried H-DNDs in dependence on the AOR treatment time. The individual spectral lines are stacked for better clarity. The modes which change their relative intensity or position are marked with arrows.

preferring termination with $\mathrm{OH}$ groups, highly susceptible to water bonding.

In the work of Petit et al., ${ }^{37}$ the $1589 \mathrm{~cm}^{-1}$ mode was attributed to non-HB water on ND's, as the frequency is identical with electron would be accepted to the water's antibonding molecular orbital, weaken the dipole strength and decrease the vibrational frequency. ${ }^{37}$

The changes of water signatures with the AOR treatment duration have to be related to the modification of the DND's surface chemistry. The surface regions decorated with polar groups, especially $\mathrm{OH}$ functions, increased in their area, attracting more water molecules. These water molecules were arranged on both hydrophilic and hydrophobic surface regions, resulting in the increase of contributions of weakly (1560-1589 $\left.\mathrm{cm}^{-1}\right)$ as well as strongly (1616-1653 $\mathrm{cm}^{-1}$ ) HBbonded water. In the FTIR spectra in Fig. 3 we can see that the $\mathrm{O}-\mathrm{H}$ bend region $\left(1565-1645 \mathrm{~cm}^{-1}\right.$ ) does not follow the highly increasing trend in the broad 3600-2800 $\mathrm{cm}^{-1} \mathrm{O}-\mathrm{H}$ stretch band with the AOR treatment time. Therefore, we assume that both water (less) and $\mathrm{OH}$ groups formed by radical treatment (more) contribute to this $\mathrm{O}-\mathrm{H}$ stretch band. In Fig. 6 and 7, details of the $\mathrm{C}=\mathrm{O}$ stretch region (maxima at 1715-1724 $\mathrm{cm}^{-1}$ ) can also be resolved. The observed formation of aldehydes by radical oxidation means that also carboxyls can be formed by further oxidation of aldehydes:

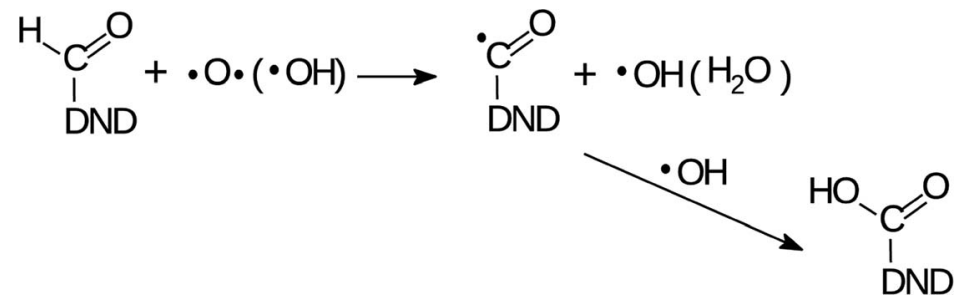

that of a water monomer in the gas phase. Fig. 6 and 7 show that this mode is missing on the reference H-DNDs and becomes more pronounced during the AOR treatment duration. Note that the peaks at $1589-1594 \mathrm{~cm}^{-1}$ can be attributed to $\mathrm{C}=\mathrm{C}$ bonds, ${ }^{41,45}$ but this can be excluded in our case since the formation of $\mathrm{C}=\mathrm{C}$ bonds is unlikely with the AOR treatment. The continuous enhancement of the $1589 \mathrm{~cm}^{-1}$ peak by the AOR treatment (apparent both on short-dried and in vacuo dried samples) is in correlation with the enhancement of the free $\mathrm{O}-\mathrm{H}$ stretch at $3695 \mathrm{~cm}^{-1}$ (see Fig. 3). A presence of this free stretch mode has previously been reported for water molecules adsorbed on hydrophobic surfaces ${ }^{47}$ However, newly formed carboxyl $(\mathrm{COOH})$ or alcohol moieties may also contribute to this peak.

The lower-lying mode $1572 \mathrm{~cm}^{-1}$ shifts during the AOR treatment down to $1564 \mathrm{~cm}^{-1}$ (see Fig. 7). This value is close to the $1560 \mathrm{~cm}^{-1}$ mode reported for hydrogenated NDs, ${ }^{37}$ where it was hypothesized to originate from water molecules near to the hydrogenated diamond surface. It is expected that such a water molecule can accept an electron from the diamond hydrogenated surface layer with negative electron affinity. This extra
In the spectra of short-dried samples (Fig. 6), the shift of the maxima of the carbonyl peak from $1715 \mathrm{~cm}^{-1}$ to $1724 \mathrm{~cm}^{-1}$ indicates the increasing ratio of carboxyls to aldehydes or ketones. On the other hand, in the spectra of in vacuo dried samples (Fig. 7), the temporal change is observed as a peak broadening. We may explain this different observation between short-dried and in vacuo dried samples by the creation of $\mathrm{HB}$ between $\mathrm{H}_{2} \mathrm{O}$ molecules and polarized $\mathrm{C}=\mathrm{O}$ bond. Simultaneous formation of new aldehydes and conversion of existing aldehydes to carboxyls will broaden the carbonyl band to both sides, as it is shown on in vacuo dried samples. However, a higher amount of adsorbed water, as in the case of short-dried samples, will affect more $\mathrm{COOH}$ groups than aldehydes thanks to the $\mathrm{O}-\mathrm{H} \cdots \mathrm{O}-\mathrm{H}$ hydrogen bond and highlight the $\mathrm{COOH}$ contribution, as demonstrated in Fig. 6.

\subsection{Morphology, size, and zeta potential of modified H-DNDs}

Fig. 8 shows a dependence of dynamic light scattering (DLS) volumetric size and zeta potential (ZP) on the AOR treatment time. 


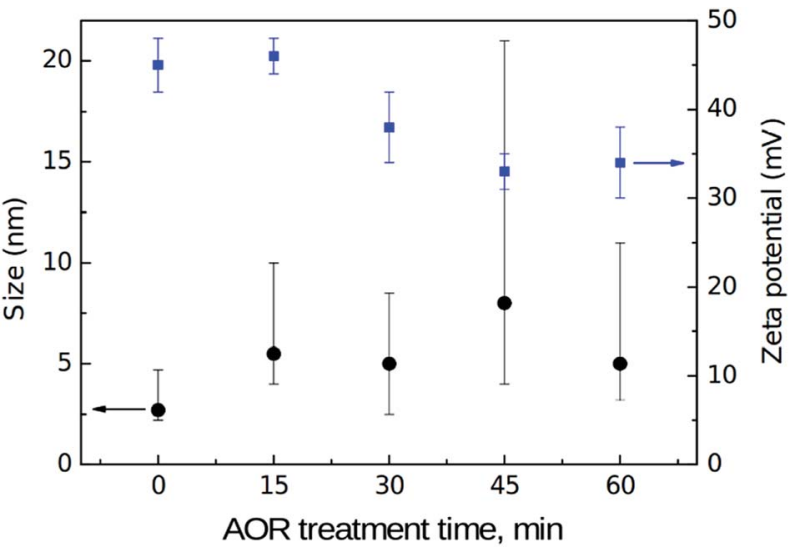

Fig. 8 DLS volumetric size (black, left) and zeta potential (blue, right) values in dependence on the AOR treatment time. Note that the "error" bars for size represent FWHM of the asymmetrical size distribution.

DLS volumetric mean size of the reference, initial H-DNDs is about $3 \mathrm{~nm}$ which is a significantly smaller size compared to the generally accepted mean size of single DND particles which is typically reported in the 4-6 $\mathrm{nm}$ range. The DLS mean size around $3 \mathrm{~nm}$ has been indeed reported several times for hydrogenated DNDs. ${ }^{6,78}$ Although the exact origin of this discrepancy remains unclear, several important factors can be still discussed. First, this is an effect of ND hydration shell which is involved in the measured DLS size. Different surface chemistry and related effects, such as the strength of hydrogen bonds between water molecules in the hydration shell, cause its different thickness on H-NDs and O-NDs. Specifically, due to weakening of the hydrogen bonds (HB) on the H-ND surface, ${ }^{37,45}$ the hydration shell of H-NDs is significantly thinner than of O-NDs resulting in DLS size discrepancy of particles with otherwise identical ND core. ${ }^{9}$ Second, hydrogen is known to be relatively efficient in disruption of the primary ND clusters (core agglutinates) ${ }^{48}$ thus helping to release truly individual DND particles. It is probably the hydrogen ability to penetrate into the ND inter-particle boundaries and react there with the ND surface, ${ }^{49}$ thus passivating the DND surface and efficiently breaking up the core agglutinates. From the results presented here and arguments, it seems that the mean size of truly de-agglutinated DND particles is around $3 \mathrm{~nm}$. Indeed, in the recent work, ${ }^{50} \mathrm{ND}$ mean size of
$3.3 \mathrm{~nm}$ was reported in the latest generation of NanoAmando ${ }^{\mathrm{TM}}$ (NanoCarbon Research Institute, Japan) colloid, which is produced by zirconia microbeads milling of a DND powder. Complex size distribution characterization of the reference $\mathrm{H}$ DNDs by means of atomic force microscopy (AFM), DLS and analytical ultracentrifuge ${ }^{9}$ can be found in ESI (Fig. S2 in the ESI). $\dagger$ With increasing time of the AOR treatment the DLS size values increases and the size distribution broadens which indicates an aggregation of the primary $3 \mathrm{~nm}$ H-DNDs. This is expressed by the (asymmetrical) error bars which represent FWHM values of an average volume distribution obtained from three subsequent DLS scans. The ZP of the reference H-DND colloid is $45 \pm 3 \mathrm{mV}$. The origin of positive $\mathrm{ZP}$ of hydrogenated NDs remains unclear although it has been tentatively attributed to protonation of $\pi$ electrons on $\mathrm{sp}^{2}$-phase carbon ${ }^{48}$ on the H-ND surface. After the AOR treatment the ZP drops down to approx. $32 \mathrm{mV}$. Possible aggregation may be awaited from the decrease of ZP although none of the samples were below a colloidal stability limit and the AOR treated colloidal solutions remained visually stable in all cases.

Fig. 9 shows AFM images of reference (a) and AOR-treated (b-e) H-DNDs deposited on $\mathrm{Si} / \mathrm{SiO}_{x}$ substrate.

Fig. 9a demonstrates very dense and even deposition of the reference $\mathrm{H}$-DNDs, forming preferentially a monolayer of mostly isolated single $\sim 3 \mathrm{~nm}$ particles which is accompanied by very low RMS value of $1.1 \mathrm{~nm}$. With increasing treatment time we observe a gradual coarsening of the deposited layer accompanied with an increase of the RMS values up to nearly $5 \mathrm{~nm}$ for the $60 \mathrm{~min}$ sample (Fig. 9e). The deposition of positively charged H-NDs to negatively charged $\mathrm{Si} / \mathrm{SiO}_{x}$ substrate is driven by electrostatic attraction. ${ }^{7,48}$ It has been shown that intentional decrease of positive $\mathrm{ZP}$ of $\mathrm{H}-\mathrm{NDs}$ to around $+30 \mathrm{mV}$, i.e. to the colloidal stability limit, may lead to very dense coverage and nucleation density., However we do not observe such an effect here. Although the AOR treatment leads to the $\mathrm{ZP}$ decrease to around $+30 \mathrm{mV}$, the AORtreated $\mathrm{H}$-DNDs rather form aggregates than a denser coverage.

The aggregation tendency is further demonstrated by the SEM analysis of the samples before and after 60 min AOR treatment. The typical SEM morphologies of the pristine and AOR-treated $\mathrm{H}$ DNDs deposited on silicon substrate are shown in Fig. 10.

SEM morphologies of both reference (Fig. 10a) and $60 \mathrm{~min}$ AOR-treated (Fig. 10b) samples corresponds well to the AFM (a)

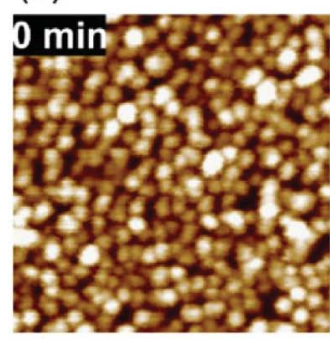

$Z$ scale: $4.5 \mathrm{~nm}$

RMS $=1.1 \mathrm{~nm}$ (b)

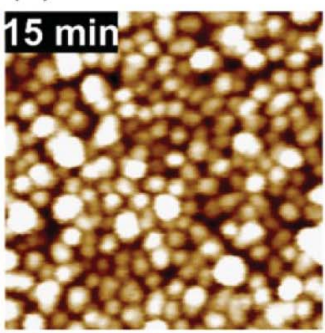

$Z$ scale: $5.5 \mathrm{~nm}$

$\mathrm{RMS}=1.3 \mathrm{~nm}$ (c)

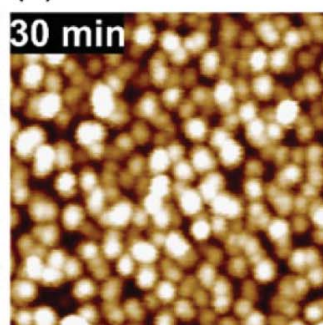

$Z$ scale: $5.5 \mathrm{~nm}$

$\mathrm{RMS}=1.4 \mathrm{~nm}$ (d)

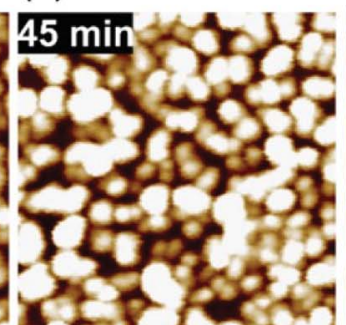

$Z$ scale: $6 \mathrm{~nm}$

$\mathrm{RMS}=2.1 \mathrm{~nm}$ (e)

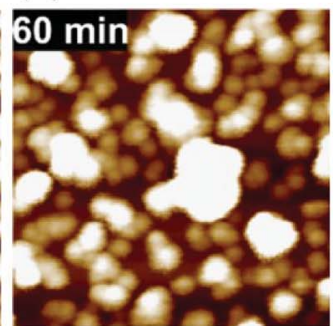

$Z$ scale: $14 \mathrm{~nm}$

RMS $=4.8 \mathrm{~nm}$

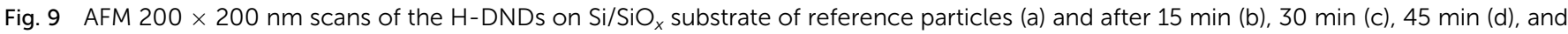
60 min (e) AOR treatment. 
(a)

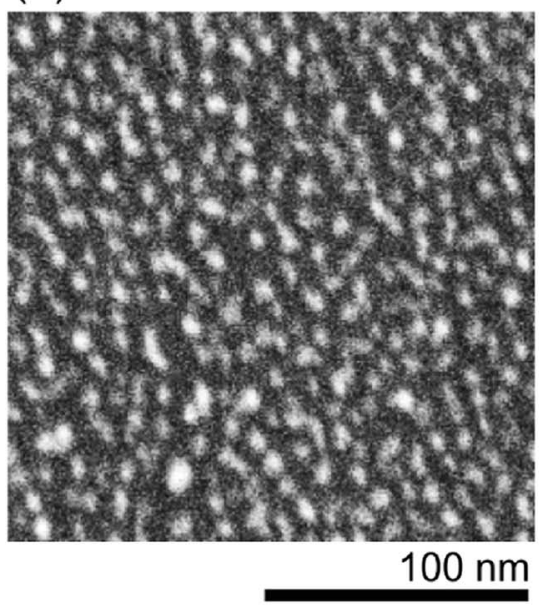

(b)

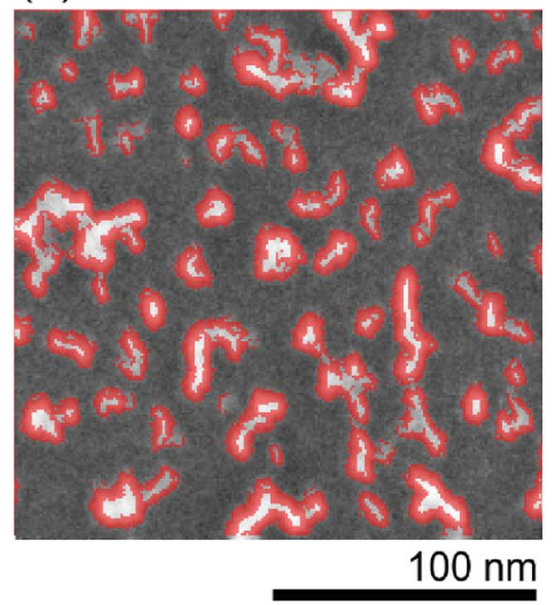

Fig. 10 SEM morphologies of reference H-DNDs (a) and 60 min AOR-treated H-DNDs (b) deposited on Si substrate. The chain-like structures are highlighted by red colour.

images (Fig. 9), although DND coverage/particle density looks seemingly higher in AFM than in SEM images. This is an artifact of the AFM measurement caused by convolution of the AFM tip with the DND particles. ${ }^{9}$ Thus, the SEM provides to some extent complementary data which are not obscured by the AFM tip convolution with the sample. The SEM analysis of the reference and 60 min AOR-treated samples reveals an obvious transition from individual particle-like to chain-like cluster (up to $50 \mathrm{~nm}$ ) deposits. This behaviour can be explained by electrostatic attraction of facets of specific crystallographic orientations which should be induced by selective oxidation of these facets by AOR.

Lai and Barnard ${ }^{51}$ calculated the strength of attraction between different pairs of hydrogenated and hydroxylated ND facets of $\{100\},\{110\}$, and $\{111\}$ orientation. They predicted that two hydroxylated $\{110\}$ facets exhibit a substantially higher aggregation probability than any other pair. As we propose that the alcohol groups are the major newly formed moieties by the AOR treatment, the specific hydroxylation of $\{110\}$ facets seems to be a possible explanation of the observed DNDs' chaining behaviour, which is hardly correlated with any particular value of ZP. The preferential attraction of selected facets would support the tendency to form chain-like aggregates rather than spherical clusters. Note that in our previous work, ${ }^{17}$ the asreceived DNDs treated in the underwater corona discharge formed long filaments after settlement. However, those filaments were 2-15 $\mu \mathrm{m}$ wide and were formed from dischargetreated $0.5-1 \mu \mathrm{m}$ clusters. Here we obtained shorter chains $(<50 \mathrm{~nm})$ mostly made from single DND particles.

\subsection{Correlation of qualitative and quantitative analyses}

The qualitative changes found in FTIR spectra can be compared with the changes in atomic composition as found by XPS. Table 2 summarizes the dependence of atomic concentrations of chemical elements $(\mathrm{O}, \mathrm{C}, \mathrm{N})$ on the AOR treatment time.

The nitrogen content had not any trend and its value $2-3 \%$ corresponds to the intrinsic $\mathrm{N}$ usually found in detonation NDs as the remnant of the detonation synthesis. ${ }^{5}$ On the other hand, the content of oxygen increased two times after the 60 min AOR treatment compared to the reference sample, with almost the entire increment achieved in the first $30 \mathrm{~min}$. This saturationlike trend in the overall oxidation as found by XPS is not entirely consistent with the continuous increase of oxygencontaining groups as revealed in the FTIR spectra. In the first estimation, the saturation should indicate a certain exhausting of the reaction sites on the H-DNDs' surface. In other words, that radicals prefer to recombine with each other rather than to react with H-DNDs. However, the saturation should be also attributed to the conversion of primary alcohols to aldehydes, which does not increase the overall O content (see reaction (2)). With view to rapidly increasing $\mathrm{O}-\mathrm{H}$ stretch and $\mathrm{C}-\mathrm{O}$ related bands, the $\mathrm{O}$ content increase in the first 30 min can be most probably related to the formation of alcohol moieties.

The trend in oxygen content is well consistent with the trend in $\mathrm{ZP}$, decrease of which also slows down after $30 \mathrm{~min}$ of the AOR treatment (see Fig. 8). It should be emphasized that the ZP represents an average value over the distribution of particles size and their possibly various surface chemistry. Since facets of different crystallographic orientation prefer chemisorption of different functional groups, ${ }^{52}$ these different facets will be charged in a different manner and contribute with both positive and negative surface charge to the overall surface potential. We have identified the formation of alcohols, aldehydes, and carboxyls during the AOR treatment. While the alcohols and aldehydes are acido-basically neutral (they do not release nor

Table 2 Concentration of chemical elements of the samples obtained from XPS spectra from AOR treated H-DNDs

\begin{tabular}{llll}
\hline AOR treatment time, min & O, at\% & C, at\% & N, at\% \\
\hline 0 & 1.9 & 95.4 & 2.7 \\
15 & 2.5 & 95.6 & 1.9 \\
30 & 3.4 & 94 & 2.6 \\
45 & 3.8 & 94.1 & 2.1 \\
60 & 3.7 & 94.3 & 2
\end{tabular}


accept $\mathrm{H}^{+}$) under $\mathrm{pH} \sim 7$, the carboxylic acids release a proton and can contribute to the negative ZP. We thus propose that the decrease in ZP is caused by the replacement of positively charged hydrogenated places with neutral alcohols and aldehydes (major contribution) and formation of negatively charged places with carboxyls (minor contribution).

\section{Conclusions}

We demonstrated a capability of $\mu$-APPJ in delivering reactive oxygen species towards the surface of individual DNDs in colloidal solution, promoting mild surface chemistry modifications with high impact on self-assembly of nanodiamonds. The main reactive mechanism was proposed as an abstraction of a hydrogen atom by $\mathrm{O}$ or $\mathrm{OH}$ radical and its exchange with the $\mathrm{OH}$ group, resulting in the increased concentration of alcohols, aldehydes and carboxyls on the DND's surface. As a specific and rather unique process for DND's chemistry, the formation of aldehydes from the radical oxidation of $-\mathrm{CH}_{3}$ groups was identified. The cross-correlation of changes during the AOR treatment between short-dried and in vacuo dried DNDs was crucial for interpreting the changes in $\mathrm{CH}$ stretch (2800$3050 \mathrm{~cm}^{-1}$ ) and $\mathrm{OH}$ bend (1565-1660 $\mathrm{cm}^{-1}$ ) spectral regions. The structural arrangement of surface water molecules also changed after the AOR treatment. The surface water molecules re-arranged on both hydrophilic and hydrophobic surface regions, resulting in the increase of contributions of weakly (1560-1589 $\left.\mathrm{cm}^{-1}\right)$ as well as strongly $\left(1616-1653 \mathrm{~cm}^{-1}\right) \mathrm{HB}-$ bonded water. Mild oxidation by AOR treatment was confirmed by the overall oxygen content increase from $1.9 \%$ to $3.7 \%$ after $30-60$ min treatments assigned mostly to the $\mathrm{OH}$ alcohol moieties. This mild oxidation led to a decrease in ZP close to the colloid-stability limit of $+30 \mathrm{mV}$ without disrupting the colloid stability, but with a large impact on H-DND morphology and aggregation tendency. The observed formation of chain-like aggregates on the Si substrate was attributed to the attraction of specific nanodiamonds facets modified by the AOR treatment.

The APPJ process can be thus an attractive alternative to more traditional methods allowing controllable, gradual, and specific surface chemistry modifications by means of radical reactions in the nanodiamond suspensions. At the same time, the AOR treatment seems as a suitable tool for tuning selfassembly of nanodiamonds on surfaces. This can be especially useful when producing ordered nanodiamond superstructures, like narrow nucleation rows for selective-area deposition of diamond in photonic devices.

\section{Conflicts of interest}

There are no conflicts to declare.

\section{Acknowledgements}

This work was supported by the Ministry of Health of the Czech Republic grant No. NV15-33018A (V. J., A. A., A. K.) and by Operational Programme Research, Development and Education financed by European Structural and Investment Funds and the Czech Ministry of Education, Youth and Sports (Project No. SOLID21 - CZ.02.1.01/0.0/0.0/16_019/0000760). S. S. acknowledges the Czech Science Foundation (GACR) grant number 1811711Y. We acknowledge O. Vanek for the AUC measurement.

\section{References}

1 D. Passeri, F. Rinaldi, C. Ingallina, M. Carafa, M. Rossi, M. L. Terranova and C. Marianecci, J. Nanosci. Nanotechnol., 2015, 15, 972-988.

2 J. C. Arnault, in Carbon Nanoparticles and Nanostructures, ed. N. Yang, X. Jiang and D.-W. Pang, Springer International Publishing, Cham, 2016, pp. 1-45.

3 J. C. Arnault and H. A. Girard, Curr. Opin. Solid State Mater. Sci., 2017, 21, 10-16.

4 J. Whitlow, S. Pacelli and A. Paul, J. Controlled Release, 2017, 261, 62-86.

5 O. A. Shenderova and G. E. McGuire, Biointerphases, 2015, 10, 30802.

6 T. Yoshikawa, V. Zuerbig, F. Gao, R. Hoffmann, C. E. Nebel, O. Ambacher and V. Lebedev, Langmuir, 2015, 31, 5319-5325.

7 J. Hees, A. Kriele and O. A. Williams, Chem. Phys. Lett., 2011, 509, 12-15.

8 O. Shimoni, J. Cervenka, T. J. Karle, K. Fox, B. C. Gibson, S. Tomljenovic-Hanic, A. D. Greentree and S. Prawer, ACS Appl. Mater. Interfaces, 2014, 6, 8894-8902.

9 S. Stehlik, M. Varga, P. Stenclova, L. Ondic, M. Ledinsky, J. Pangrac, O. Vanek, J. Lipov, A. Kromka and B. Rezek, ACS Appl. Mater. Interfaces, 2017, 9, 38842-38853.

10 J. M. Rosenholm, I. I. Vlasov, S. A. Burikov, T. A. Dolenko and O. A. Shenderova, J. Nanosci. Nanotechnol., 2015, 15, 959971.

11 V. N. Mochalin and Y. Gogotsi, Diamond Relat. Mater., 2015, 58, 161-171.

12 H. A. Girard, J. C. Arnault, S. Perruchas, S. Saada, T. Gacoin, J.-P. Boilot and P. Bergonzo, Diamond Relat. Mater., 2010, 19, 1117-1123.

13 H. Kozak, Z. Remes, J. Houdkova, S. Stehlik, A. Kromka and B. Rezek, J. Nanopart. Res., 15, 1568-1575.

14 A. Kromka, J. Čech, H. Kozak, A. Artemenko, T. Ižák, J. Čermák, B. Rezek and M. Černák, Phys. Status Solidi B, 2015, 252, 2602-2607.

15 V. Jirásek, J. Čech, H. Kozak, A. Artemenko, M. Černák and A. Kromka, Phys. Status Solidi A, 2016, 213, 2680-2686.

16 P. J. Bruggeman, M. J. Kushner, B. R. Locke, et al., Plasma Sources Sci. Technol., 2016, 25, 53002.

17 V. Jirásek, P. Lukě̌, H. Kozak, A. Artemenko, M. Člupek, J. Čermák, B. Rezek and A. Kromka, RSC Adv., 2016, 6, 2352-2360.

18 H. Kozak, A. Artemenko, J. Čermák, V. Švrček, A. Kromka and B. Rezek, Vib. Spectrosc., 2016, 83, 108-114.

19 P. Stenclova, V. Celedova, A. Artemenko, V. Jirasek, J. Jira, B. Rezek and A. Kromka, RSC Adv., 2017, 7, 38973-38980.

20 X. Lu and K. Ostrikov, Appl. Phys. Rev., 2018, 5, 31102.

21 S. Reuter, T. von Woedtke and K.-D. Weltmann, J. Phys. D: Appl. Phys., 2018, 51, 233001. 
22 S. Wu, Y. Cao and X. Lu, IEEE Trans. Plasma Sci., 2016, 44, 134-151.

23 K.-D. Weltmann and T. von Woedtke, Plasma Phys. Controlled Fusion, 2017, 59, 14031.

24 K. Ostrikov, E. C. Neyts and M. Meyyappan, Adv. Phys., 2013, 62, 113-224.

25 O. V. Penkov, M. Khadem, W.-S. Lim and D.-E. Kim, J. Coat. Technol. Res., 2015, 12, 225-235.

26 Y. Gorbanev, D. O'Connell and V. Chechik, Chem.-Eur. J., 2016, 22, 3496-3505.

27 M. M. Hefny, C. Pattyn, P. Lukes and J. Benedikt, J. Phys. D: Appl. Phys., 2016, 49, 404002.

28 S. Reuter, J. Winter, S. Iseni, A. Schmidt-Bleker, M. Dunnbier, K. Masur, K. Wende and K.-D. Weltmann, IEEE Trans. Plasma Sci., 2015, 43, 3185-3192.

29 J. Benedikt, D. Schröder, S. Schneider, G. Willems, A. Pajdarová, J. Vlček and V. Schulz-von der Gathen, Plasma Sources Sci. Technol., 2016, 25, 45013.

30 T. Murakami, K. Niemi, T. Gans, D. O'Connell and W. G. Graham, Plasma Sources Sci. Technol., 2013, 22, 45010.

31 M. D. Ionita, S. Vizireanu, S. D. Stoica, et al., Eur. Phys. J. D, 2016, 70, 31.

32 S. P. Hong, T. H. Kim and S. W. Lee, Carbon, 2017, 116, 640647.

33 J. Golda, J. Held, B. Redeker, M. Konkowski, P. Beijer, A. Sobota, G. Kroesen, N. S. J. Braithwaite, S. Reuter, M. M. Turner, T. Gans, D. O'Connell and V. Schulz-von der Gathen, J. Phys. D: Appl. Phys., 2016, 49, 84003.

34 D. Ellerweg, J. Benedikt, A. von Keudell, N. Knake and V. Schulz-von der Gathen, New J. Phys., 2010, 12, 13021.

35 R. M. Silverstein, F. X. Webster, D. J. Kiemle and D. L. Bryce, Spectrometric identification of organic compounds, Wiley, Hoboken, NJ, 8th edn, 2015.

36 G. Socrates, Infrared and Raman characteristic group frequencies: tables and charts, Wiley, Chichester, 3rd edn, as paperback, 2010.
37 T. Petit, L. Puskar, T. Dolenko, et al., J. Phys. Chem. C, 2017, 121, 5185-5194.

38 T. Petit and L. Puskar, Diamond Relat. Mater., 2018, 89, 5266.

39 T. Jiang and K. Xu, Carbon, 1995, 33, 1663-1671.

40 S. Ji, T. Jiang, K. Xu and S. Li, Appl. Surf. Sci., 1998, 133, 231238.

41 O. Shenderova, A. M. Panich, S. Moseenkov, S. C. Hens, V. Kuznetsov and H.-M. Vieth, J. Phys. Chem. C, 2011, 115, 19005-19011.

42 V. Jirásek, H. Kozak and Z. Remě̌, Adv. Sci., Eng. Med., 2015, 7, 275-278.

43 T. A. Newton, J. A. Boiani and M. A. Hines, Surf. Sci., 1999, 430, 67-79.

44 J. Benedikt, M. Mokhtar Hefny, A. Shaw, B. R. Buckley, F. Iza, S. Schäkermann and J. E. Bandow, Phys. Chem. Chem. Phys., 2018, 20, 12037-12042.

45 S. Stehlik, T. Glatzel, V. Pichot, R. Pawlak, E. Meyer, D. Spitzer and B. Rezek, Diamond Relat. Mater., 2016, 63, 97-102.

46 V. N. Mochalin, I. Neitzel, B. J. M. Etzold, A. Peterson, G. Palmese and Y. Gogotsi, ACS Nano, 2011, 5, 7494-7502.

47 L. F. Scatena, Science, 2001, 292, 908-912.

48 O. A. Williams, J. Hees, C. Dieker, W. Jäger, L. Kirste and C. E. Nebel, ACS Nano, 2010, 4, 4824-4830.

49 A.-I. Ahmed, S. Mandal, L. Gines, O. A. Williams and C.-L. Cheng, Carbon, 2016, 110, 438-442.

50 V. I. Korepanov, H. Hamaguchi, E. Osawa, V. Ermolenkov, I. K. Lednev, B. J. M. Etzold, O. Levinson, B. Zousman, C. P. Epperla and H.-C. Chang, Carbon, 2017, 121, 322-329.

51 L. Lai and A. S. Barnard, J. Phys. Chem. Lett., 2012, 3, 896901.

52 A. S. Barnard, Nanoscale, 2018, 10, 8893-8910. 